\title{
Granulomatous mycosis fungoides - A diagnostic challenge*
}

\author{
Catharina Maria Freire de Lucena Pousa ${ }^{1}$ \\ Danielle Mann ${ }^{3}$ \\ Maria de Fátima Gonçalves Scotelaro Alves ${ }^{2}$
}

\author{
Natália Solon Nery² \\ Daniel Lago Obadia ${ }^{2,4}$
}

DOI: http:/ / dx.doi.org/10.1590/abd1806-4841.20153460

\begin{abstract}
Granulomatous mycosis fungoides is a rare subtype of T-cell cutaneous lymphoma. Due to its clinical heterogenicity the diagnosis is delayed and based on histopathological and immuno-histochemical findings, sometimes requiring gene rearrangement studies for confirmation. We report the case of a patient who was submitted to several biopsies before diagnostic conclusion.
\end{abstract}

Keywords: Granuloma; Lymphoma, T-Cell, cutaneous; Mycosis fungoides

\section{INIRODUCTION}

Granuloma formation has been reported in various types of lymphomas such as Sézary syndrome, cutaneous anaplastic large cell lymphoma, subcutaneous panniculitis-like T-cell lymphoma, primary cutaneous B-cell lymphoma. However, mycosis fungoides is the most common form of primary cuta-neous lymphoma which may present granulomatous infiltrate. ${ }^{1}$

Due to the fact that it lacks a specific clinical feature and that the granulomatous inflammatory infil-trate sometimes is extensive, this disease may be mistakenly diagnosed as granulomatous dermatitis, and the diagnosis of lymphoma may be postponed.

\section{CASE REPORT}

A 88-year-old female patient presented with an asymptomatic erythematous plaque on her neckline, which had developed 2 years

previously. She was diagnosed with profound mycosis, and used medium-power topical steroids and topical and oral antifungal azole, with no improvement.
The patient first visited our hospital 6 months ago, when we found a $20 \times 12 \mathrm{~cm}$ erythematousviolet plaque with yellowish milia-type papules and telangiectasia in the anterior chest region. Subsequently she developed purpuric lesions in the vicinity of the lesion (Figure 1)

Three histopathological examinations of the lesion were performed, and the first two showed granu-lomatous reaction with epithelial cells in the reticular dermis (Figures 2 and 3). The special stains performed (Fite, Grocott, PAS) failed to show microorganisms. The last histopathological examination revealed, other than the tuberculoid granuloma, an area of epidermotropism (Figure 4). The immunohistochemical study was positive for CD3-, CD4-, and CD5-lymphocytes and weakly positive for CD8. The study showed no immunostaining for CD30.

Blood count, complete biochemical profile, electrolytes, protein immunoelectrophoresis, PPD, com-puted tomography of the chest and abdomen, cervical spine X-ray and biopsy of abdominal fat were all normal.

Approved by the Advisory Board and accepted for publication on 07.04.2014.

* Study conducted at the Pedro Ernesto University Hospital, University of the State of Rio de Janeiro (HUGG-UNIRIO), Rio de Janeiro (RJ), Brazil. 


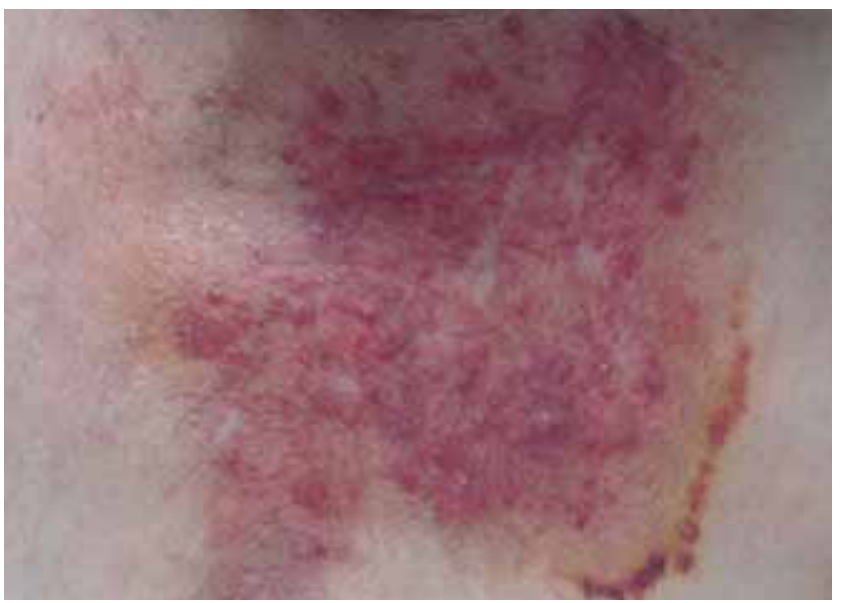

FIGURE 1: Erythematous-purpuric plaque with protruding papules and milium, and telangiectasia in the anterior chest region

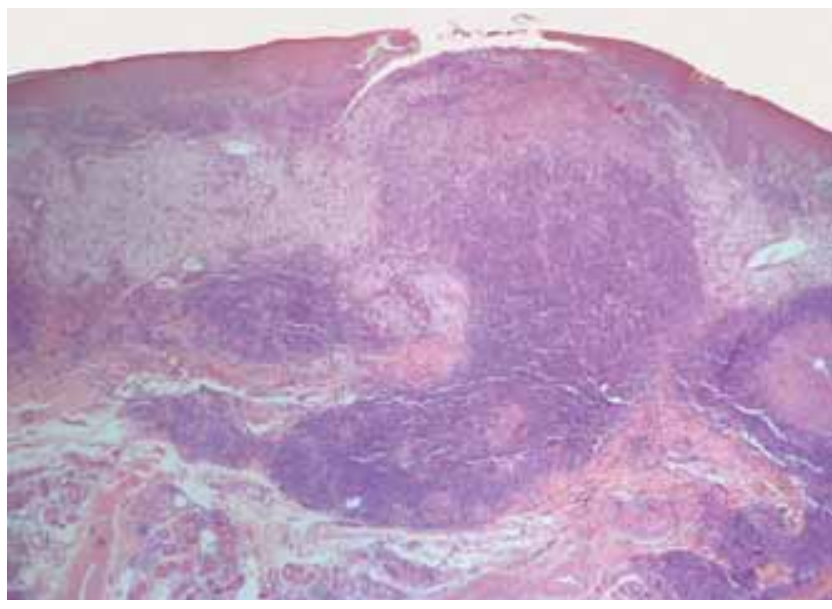

FIgURE 2: Histopathological examination showing granulomatous inflammation in the dermis HE 40x

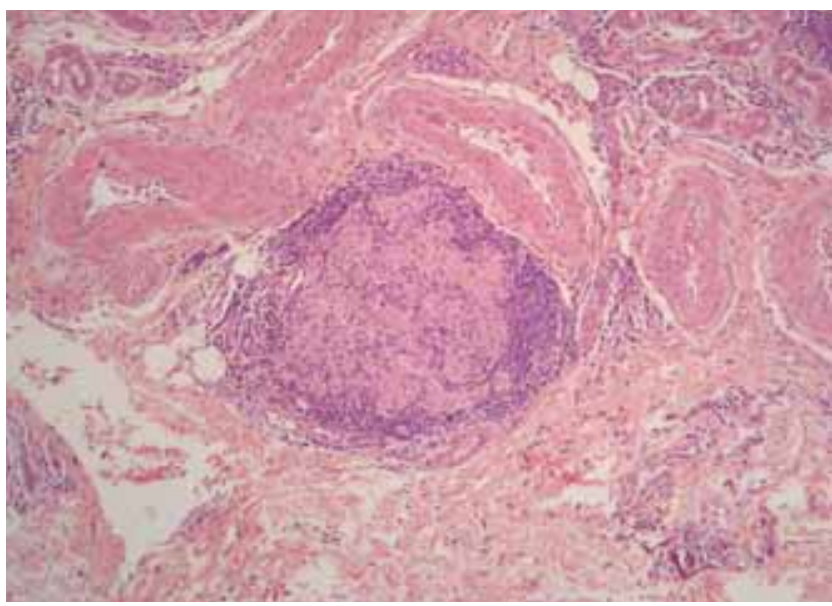

FIGURE 3: Detail of a epithelioid cells granuloma. HE 100x

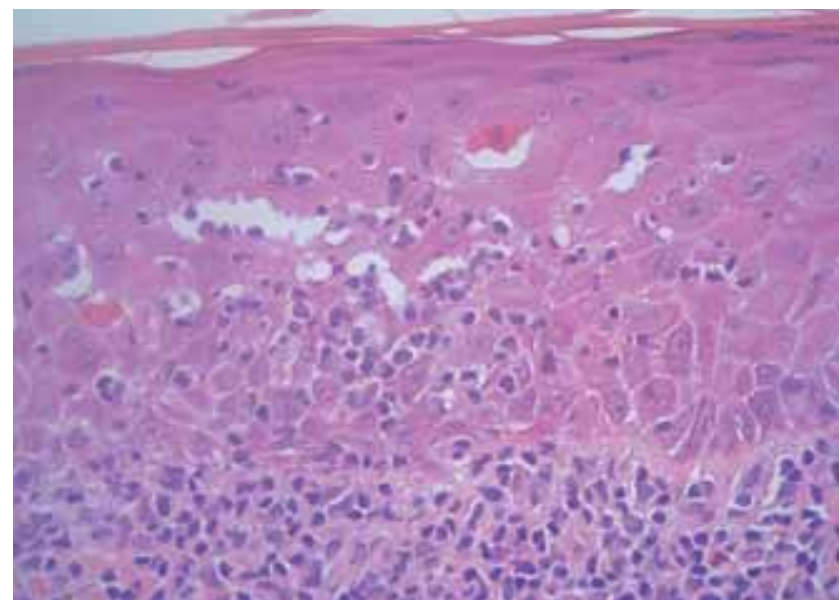

FiguRE 4: Area of epidermotropism and dermal invasion by an infiltrate with pleomorphic atypical lymphocytes. HE 200x

The initially proposed treatment was highpower topical steroids, but the patient stopped to attend the follow-up visits.

\section{DISAUSSION}

Mycosis fungoides granulomatous was first described by Ackerman and Flaxman in 1970. ${ }^{1,2}$ Histopathologically, it is characterized by diffuse infiltration of the dermis by lymphoid cells with hyperconvoluted nuclei and interspersed with granulomatous inflammatory foci with epithelioid and giant cells. It is more common in males between the 5th and 6th decades of life. Clinical presentation is variable. It may present as papules, plaques or ulcerated nodules. ${ }^{2}$

The diagnosis of mycosis fungoides granulomatous is established after a granulomatous infiltrate is seen. Occasionally, a dense inflammatory infiltrate with pleomorphic atypical lymphocytes is present in the subcutaneous area. Epidermotropism is considered a critical finding to make this diagnosis. When there is no epidermotropism, diagnostic delay is, on average, nine years and the diagnosis is usually only made after several biopsies. ${ }^{2.3}$

Various granulomatous histopathological patterns are associated with cutaneous lymphoma, the most common being the epithelioid. However, there are reports in the literature about forms that also mimic annular granuloma, lipoid necrobiosis, granulomatous rosacea and granulomatous panniculitis. More than one pattern may coexist in the same patient. ${ }^{1,3,4,5}$

The etiopathogenic mechanism of granuloma formation is unknown. It was suggested that the granulomatous reaction occurs due to the secretion of 
chemotactic factors by neoplastic cells. A polarization to produce Th1 cytokines, such as interleukin-2, interferon-gamma, and tumor necrosis factor-alpha, may also occur. On the other hand, the granuloma may precede the lymphoma, with macrophages producing interleukin-6, which promotes lymphocyte proliferation. ${ }^{4}$

\section{REFERENCES}

1. Gutte R, Kharkar V, Mahajan S, Chikhalkar S, Khopkar U. Granulomatous mycosis fun-goides with hypohidrosis mimicking lepromatous leprosy. Indian J Dermatol Venereol Lep-rol. 2010;76:686-90

2. Kempf W, Ostheeren-Michaelis S, Paulli M, Lucioni M, Wechsler J, Audring H, AL. Granulomatous mycosis fungoides and granulomatous slack skin. Ar Arch Derma-tol. 2008;144:1609-17.

3. Telle H, Koeppel MC, Jreissati M, Andrac L, Horschowski N, Sayag J. Granulomatous mycosis fungoides. Eur J Dermatol. 1998;8:506-10.

4. Gallardo F, García-Muret MP, Servitje 0, Estrach T, Bielsa I, Salar A, et al. Cutaneous lymphomas showing prominent granulomatous component: clinicopathological features in a series of 16 cases. J Eur Acad Dermatol Venereol. 2009;23:639-47.

5. Fargnoli MC, Peris K, Francesconi F, Cantonetti M, Cerroni L, Chimenti S. Granulomatous mycosis fungoides responsive to gemcitabine. Eur J Dermatol. 2002;12:479-81.
Some authors believe that the granuloma represents a host's attempt to stop the lymphoma, thus indicating good prognosis. However, literature reviews indicate that this finding does not change the course of the disease. ${ }^{3,4}$

Treatment does not differ from that of other forms of mycosis fungoides, varying according to the clinical stage of the patient. Systemic chemotherapy is reserved for more advanced, diffuse or tu-moral forms of the disease. ${ }^{5}$

\author{
M AILING ADDRESS: \\ Catharina M aria Freire D e Lucena Pousa \\ Boulevard 28 de setembro, 77 \\ Vila Isabel \\ 20.551-030 Rio de Janeiro, RJ, Brazil. \\ E-mail: catharinamaria@hotmail.com
}

How to cite this article: Lucena CMF, Nery NS, Obadia DL, Alves MFGS. Granulomatous mycosis fungoides - A diagnostic challenge. An Bras Dermatol. 2015;90(4):554-6. 